\title{
GIVING COMMITMENT: EMPLOYEE SUPPORT PROGRAMS AND THE PROSOCIAL SENSEMAKING PROCESS
}

\author{
ADAM M. GRANT \\ JANE E. DUTTON \\ BRENT D. ROSSO \\ University of Michigan
}

University of North Carolina at Chapel Hill

\begin{abstract}
Researchers have assumed that employee support programs cultivate affective organizational commitment by enabling employees to receive support. Using multimethod data from a Fortune 500 retail company, we propose that these programs also strengthen commitment by enabling employees to give support. We find that giving strengthens affective organizational commitment through a "prosocial sensemaking" process in which employees interpret personal and company actions and identities as caring. We discuss theoretical implications for organizational programs, commitment, sensemaking and identity, and citizenship behaviors.
\end{abstract}

Changing employment landscapes have weakened employees' physical, administrative, and temporal attachments to organizations (Cascio, 2003; Pfeffer \& Baron, 1988). Employees are more mobile, more autonomous, and less dependent on their organizations for employment than ever before. To address these challenges, organizations are increasingly seeking to strengthen employees' psychological attachments by cultivating affective commitment-an attitude of emotional dedication-to organizations (Mathieu \& Zajac, 1990; Meyer \& Allen, 1991). Extensive research has demonstrated that affective commitment to organizations is linked to important behavioral outcomes ranging from decreased absenteeism and turnover to increased job performance (Cooper-Hakim \& Viswesvaran, 2005; Riketta, 2002; Somers, 1995). Accordingly, scholars and practitioners continue to share a deep interest in understanding how affective commitment to organizations develops. This pursuit is a foundational task for organizational scholarship (Mowday \& Sutton, 1993).

For helpful feedback and suggestions, we are grateful to Associate Editor Brad Kirkman, three anonymous reviewers, Jeff Edwards, Nancy Rothbard, and Jim Westphal. For their assistance with data collection and coding, we offer special thanks to our project liaisons (Thom Bales, Sarah Baumann, Barbara Kinzer), research assistants (Alex Jaffe, Shanna Goldenberg, Brett Lavery, Heather Ross, Jana Bek, Katie Benedetto, Emily Feldman, Caroline Martin, Krista Wagner, Adrienne Waller), and survey and interview participants. We also thank Ben Rosen and members of the Relationships Reading Community for their advice and encouragement.
Searching for new ways to strengthen employees' affective commitment, many organizations have adopted employee support programs (Hartwell, Steele, French, Potter, Rodman, \& Zarkin, 1996). Employee support programs are formalized practices designed to improve employees' experiences at work by providing emotional, financial, and instrumental assistance beyond the scope of standard HR pay, benefit, recognition, and training and development programs. These increasingly common programs, ranging from employee assistance programs to work-family programs such as child care and elder care, provide employees with various forms of help and aid (Cascio, 2003; Edwards \& Rothbard, 2000; Goodstein, 1995). Scholars typically assume that employee support programs cultivate commitment by enabling employees to receive support (Johnson, 1986; Perry-Smith \& Blum, 2000; Trice \& Beyer, 1984). When employees become aware of or utilize the services offered by support programs, they are more likely to feel that their work organizations value their well-being and thus reciprocate by developing affective commitment to these organizations. For example, the literature on perceived organizational support suggests that when employees feel supported by their organizations, they develop beliefs that their organizations care about their welfare, which further motivate them to strengthen their affective commitment to their organizations (Rhoades \& Eisenberger, 2002). Scholars writing within this literature draw on social exchange theory (Blau, 1964; Emerson, 1976; Homans, 1958) to propose that employees form attachments to reciprocate what they have 
received from organizations. However, researchers have noted that there are additional pathways through which commitment develops, calling for a broader understanding of the underlying mechanisms (Fuller, Barnett, Hester, \& Relyea, 2003). In particular, researchers have criticized social exchange perspectives for relying on the assumption of rational self-interest (Meglino \& Korsgaard, 2004): employee support programs are assumed to strengthen commitment by fulfilling employees' self-interested motives to receive. Researchers have yet to explore the possibility that employee support programs may strengthen commitment by fulfilling employees' other-interested motives to give.

Our objective in this article is to fill this gap by offering an expanded view of the other-interested mechanisms through which employee support programs cultivate affective organizational commitment. Although employee support programs were initially formed to allow employees to receive support, it is increasingly common for these programs to allow employees to participate in giving as well as receiving (Cascio, 2003; Pfeffer, 2006). For example, through support programs in the airline, auto, construction, and railroad industries, employees are provided with opportunities to volunteer as a means of supporting coworkers (Bacharach, Bamberger, \& McKinney, 2000). At Southwest Airlines and DaVita, employees are able to donate money to programs supporting fellow employees facing medical and financial emergencies (Pfeffer, 2006). Similar programs exist at Domino's Pizza, The Limited, Jackson Hospital, and First Energy Corporation, where employees can give financial and emotional support to fellow employees in need. Our focus in this article is on these types of internal employee support programs, which are structured so that employees have the opportunity to give as well as receive.

We propose that the act of giving to support programs strengthens employees' affective commitment to their organization by enabling them to see themselves and the organization in more prosocial, caring terms. We examined the specific processes through which giving-based commitment unfolds, using a combination of qualitative and quantitative data from a Fortune 500 retail organization that manages an employee support program providing financial, material, and educational assistance to employees. In Study 1, we developed theory from interview data to deepen knowledge about the mechanisms through which giving builds commitment. In Study 2, we used quantitative survey data to conduct an exploratory test of these mechanisms as mediators of the relationship between giving behavior and commitment. Our research offers a novel framework for explaining how support programs cultivate affective organizational commitment, introduces giving as a new antecedent of affective commitment, identifies two "prosocial sensemaking" mechanisms to account for this relationship, and addresses calls to move beyond social exchange theory as a means of understanding antecedents of affective commitment.

\section{EMPLOYEE SUPPORT PROGRAMS AND COMMITMENT}

Commitment is a key concept for explaining relationships between individuals and organizations (Mathieu \& Zajac, 1990; Mowday \& Sutton, 1993). We focus on organizations as commitment targets for both theoretical and practical reasons. From a theoretical perspective, we seek to deepen existing knowledge about how organizational programs affect employees' psychological attachments to their work organizations. From a practical perspective, organizational commitment is a strong predictor of decreased absenteeism and turnover (for a review, see Meyer, Stanley, Herscovitch, and Topolnytsky [2002]). Understanding how organizational commitment develops can assist organizations in efforts to increase employee retention, which is important in industries in which organizations struggle to retain employees, such as the retail and service industries (Cascio, 2003).

Recognizing that organizational commitment can take multiple forms, we focus specifically on affective organizational commitment. Many organizational commitment researchers distinguish among three commitment forms: affective, normative, and continuance (Meyer \& Allen, 1991). Whereas normative and continuance commitment often involve feelings of obligation or pressure to be attached, affective commitment involves feelings of intrinsic motivation and self-determination (Meyer, Becker, \& Vandenberghe, 2004). As a result, affective commitment is likely to be more consistently associated with constructive attitudes and behaviors than continuance and normative commitment. In a metaanalysis of the organizational commitment literature, Meyer et al. (2002) found that relative to normative and continuance commitment, affective commitment is associated with the most favorable outcomes for both employees and organizations, such as high job performance, attendance, and organizational citizenship behavior, as well as low turnover, stress, and work-family conflict. In light of these benefits of affective organizational commitment, it is theoretically and practically important to understand how employee support programs may facilitate it. 


\section{How Employee Support Programs Cultivate Affective Organizational Commitment}

The prevailing theoretical perspective for explaining how employee support programs cultivate affective organizational commitment is based on the central tenet of social exchange theory: individuals reciprocate what they receive (Blau, 1964; Emerson, 1976; Homans, 1958). Researchers studying perceived organizational support have drawn on this theory to explain the development of affective commitment to organizations, proposing that in exchange for receiving support from organizations, employees reciprocate with emotional dedication (Rhoades \& Eisenberger, 2002). When organizations offer help and assistance through employee support programs, employees are assured that the organization is willing to meet their material and socioemotional needs (Rhoades \& Eisenberger, 2002). Employees interpret this support as a signal that the organization values and cares about their well-being, and following the norm of reciprocity, they are motivated to reciprocate by developing a stronger emotional bond with the organization. Corroborating this hypothesis, cross-lagged longitudinal research indicates that earlier perceptions of support from an organization predicted increases in affective commitment to the organization, but not vice versa (see Rhoades \& Eisenberger, 2002). This evidence suggests that when support programs enable employees to receive support, they are likely to respond with increased affective commitment to their organization.

\section{From Receiving to Giving}

We suggest that there is a second plausible pathway, which has not been previously examined, through which employee support programs may strengthen commitment. The rise of support programs designed to allow employees to give as well as receive provides an opportunity for scholars to understand an other-interested process through which support programs may strengthen commitment. We propose that the act of giving has the potential to strengthen employees' affective commitment to an organization by changing the way that employees see themselves and the organization. Previous research suggests that many employees hold prosocial identities-they define themselves as giving, caring individuals (Aquino \& Reed, 2002)—and often describe constructing and maintaining these prosocial identities as one of their most important motives, values, and guiding principles in life (see Grant, 2007, 2008a).

Building on this evidence, we explore how the act of giving to employee support programs strengthens employees' affective commitment to their organization, over and above the gain in commitment that might derive from the experience of receiving support from these programs. Studies of individual helping suggest that the act of giving to a recipient can increase the giver's commitment to that recipient: individuals make sense of giving behaviors by inferring that they like and value the recipient (Aronson, 1999; Flynn \& Brockner, 2003). We draw on this tradition in our efforts to elaborate the mechanisms through which giving to others through organizational programs strengthens affective organizational commitment. We also seek to investigate whether giving strengthens commitment when an organizational program manages the giving process. To accomplish these goals and address this gap in knowledge about whether and how giving to employee support programs increases affective organizational commitment, we conducted multimethod research at a Fortune 500 retail corporation, which we have given the pseudonym "Big Retail.”

\section{Research Context}

Big Retail manages an internal support program, which we have named the "Employee Support Foundation" (ESF), and which operates as an independent not-for-profit arm of the company to support employees in need. This charitable foundation serves employee needs beyond the scope of traditional employee assistance programs (EAPs), which provide informational and emotional assistance to employees experiencing personal problems affecting their work (Johnson, 1986). The ESF is also unlike many charitable foundations in that its mission is to strengthen the Big Retail community through internally focused programs that support employees rather than external stakeholders or recipients. In particular, the ESF provides an outlet for Big Retail employees to help each other in times of financial need.

The ESF's two primary initiatives are financial grants and educational scholarships. Big Retail employees are encouraged to contribute to the ESF to help fellow employees, and also to seek support from the ESF when facing financial difficulties themselves. The potential tie between the employee and the ESF begins when employees are first hired at Big Retail. During orientation, training sessions include the distribution of information about the ESF, as well as discussion of the ESF by orientation leaders. The policies surrounding involvement with the ESF leave considerable freedom for whether and how employees can partici- 
pate. The company allows employees to seek support from the ESF by approaching their managers directly, by visiting the ESF website, or by calling an ESF phone number. The company also allows employees to give support to other employees via the ESF by donating money from their paychecks and organizing fundraisers. However, the direct recipient of employees' donations is the ESF, which disburses funds to qualified recipients. Thus, as is common in employee support programs, employees' experiences of giving to the ESF involve interactions with the company rather than direct interactions with recipients, who remain anonymous.

\section{Overview of Research}

We collected qualitative and quantitative data at Big Retail's ESF to build and test theory about the mechanisms through which giving to a support program enhances employees' affective commitment to the organization. In Study 1, we used qualitative data from 40 interviews with Big Retail managers and associates to identify two prosocial sensemaking mechanisms through which giving cultivates commitment by enabling employees to see themselves and the company in more caring terms. In Study 2, we utilized quantitative survey data from 249 Big Retail employees to provide an initial test of the giving-commitment relationship, as mediated by the two prosocial sensemaking mechanisms identified in the qualitative data. The theoretical model that we developed and tested suggests that after giving to a support program, employees interpret their actions and the company's actions as caring, which reinforces both their personal prosocial identities as caring individuals and the company's prosocial identity as a caring organization. As a result of feeling gratitude to the company for reinforcing their personal prosocial identities and pride in the company for holding a collective prosocial identity, employees develop stronger affective commitment to the company.

\section{STUDY 1 METHODS}

\section{Sample}

We conducted 40 semistructured interviews at Big Retail in February and March 2006. We chose to conduct interviews so that we could gather qualitative data, which are particularly appropriate for constructing and elaborating theory (Lee, Mitchell, \& Sablynski, 1999). Participants were 20 store managers and 20 store associates (16 male, 24 female) at 20 Big Retail stores across the United States. At each of the 20 stores, we interviewed two employees by telephone: one manager and one associate. Managers were responsible for overseeing store operations, coordinating and delegating tasks, supervising associates, communicating with regional supervisors, and administering the store budget. Associates were responsible for product sales, customer service, merchandising, inventory processing, and distribution.

With the help of the human resources department, we strategically sampled from Big Retail stores to achieve proportional representation of the company's geographic locations, store types, and store contributions to the ESF. In terms of geography, we interviewed employees from stores in 23 states across the United States. In terms of store types, 14 were large free-standing buildings, and 6 were smaller mall stores; this distribution was proportional to the representation of these store types in the corporation. In terms of store contributions to the ESF, we selected the 10 highest-contributing stores and the 10 lowest-contributing stores in the company, basing these clarifications on the percentage of employees donating to the ESF from their paychecks. We expected that the variations in geographic location and store type would increase the generalizability of our sample, and that the variations in store contributions would provide a valuable contrast between employees who were frequently engaged versus infrequently engaged in giving through the ESF.

\section{Data Collection}

Our interviews focused on understanding employees' relationships with the ESF and Big Retail. We introduced the interviews by explaining that we were conducting a needs assessment for the ESF and were also interested in learning about how the ESF affected employees' feelings about the company. We collected employees' accounts (Orbuch, 1997), or explanations, of how they thought, felt, and acted in their encounters and relationships with the ESF and the company. We focused particular attention on two interrelated types of accounts: accounts of exchange, in which employees described giving to and receiving from the ESF, and accounts of organizational commitment, in which employees described their feelings of dedication and attachment to Big Retail. The interviews were divided into three core phases. In the first phase of the interviews, we opened with an icebreaker question about employees' responsibilities and typical workdays. In the second phase, we inquired about employees' relationships with the company. We asked employees to describe why they work for the 
FIGURE 1

\section{Study 1 Prosocial Sensemaking Model of Giving-Based Commitment}

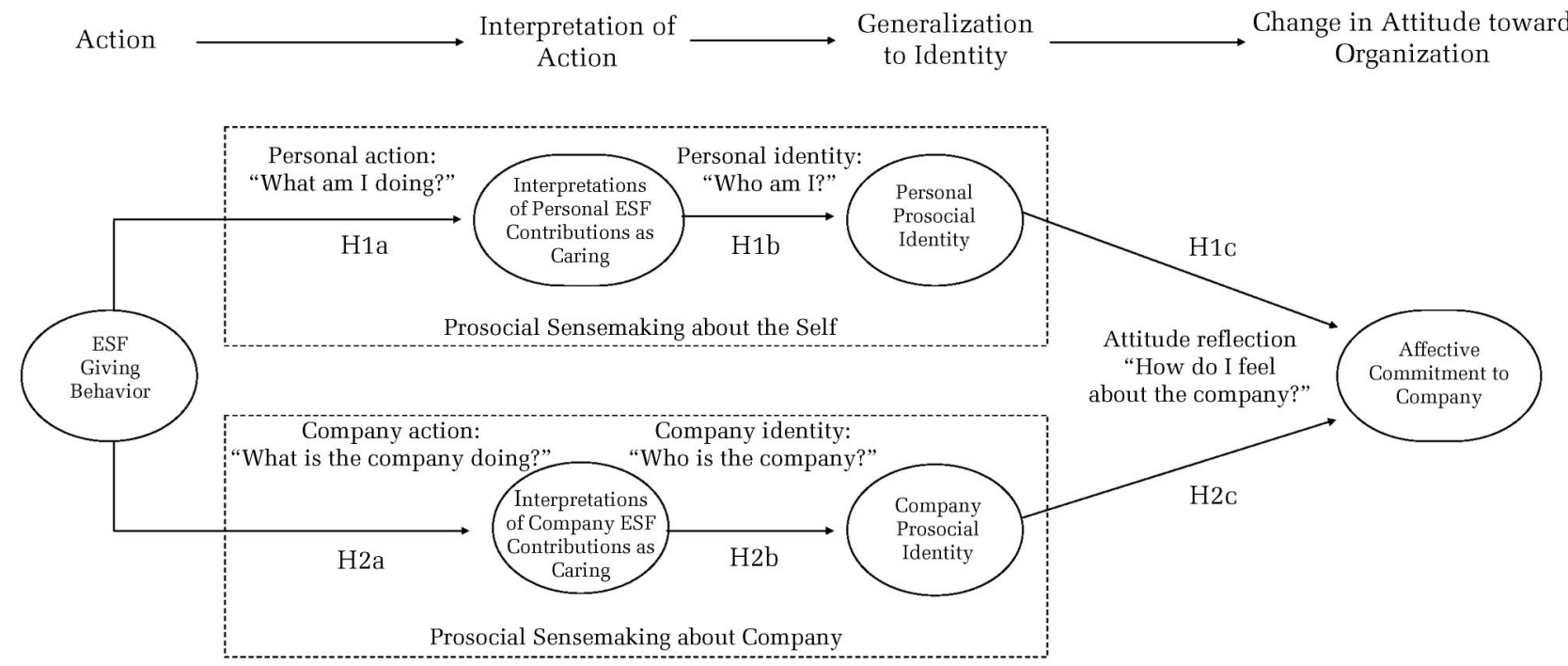

company, how attached they feel to the company, what the company's mission and values are, and how their identities relate to the company's identity. In the third phase, we explored employees' experiences with the ESF, asking them to discuss what they know about the ESF's activities, what involvement they have had with it, how important it is, what impacts it has had, and whether they have benefited from or contributed to it. The interviews lasted between 25 and 70 minutes, and we tape-recorded and transcribed them for data analysis.

\section{Data Analysis}

We identified themes by utilizing an inductive approach in which we iteratively traveled back and forth between the interview transcripts and our emerging theoretical understandings (Glaser \& Strauss, 1967). All three authors began by reading through all of the transcripts and generating initial lists of categories for classifying participants' responses. We integrated our lists with a coding scheme specifying that statements would be classified as receiving when employees described the ESF in terms of receiving help and support, and as giving when employees described the ESF in terms of giving help and support. Using this coding scheme, two independent raters blind to the research questions coded all of the interview transcripts for mentions of receiving and giving. The overall agreement rate between the two coders was 81.94 percent, and discrepancies were resolved by a third coder.
With these codes, we sought to address our research question about how employees explain why giving to an employee support program cultivates affective organizational commitment. The key data for this analysis consisted of a set of passages culled by the two independent raters in which employees mentioned giving. The first author read through these passages to generate first-order informant codes, or open codes, which comprised words used by employees to describe why they were committed to the company. We then met as a group to revise the first-order codes and generate aggregate codes to encapsulate the first-order codes under key themes. Through discussions, we abstracted these aggregate codes into core theoretical categories, which are displayed in Figure 1.

\section{STUDY 1 FINDINGS}

Our findings suggest that giving initiates a process of prosocial sensemaking, in which giving leads employees to judge personal and company actions and identities as caring, and thereby strengthens their affective commitment to the company. Figure 1 depicts our findings in the form of an emergent conceptual model, which draws on the following tenets of theoretical perspectives on sensemaking (Weick, 1995) and self-perception (Bem, 1972): (1) Actions trigger efforts to interpret and explain the actions, (2) employees generalize these interpretations to form inferences about the identities of the actors, and (3) identities provide a basis for forming and changing attitudes toward the actors. As revealed in this context, our findings sug- 
gest that giving behavior triggers a particular form of sensemaking-prosocial sensemaking-about oneself and one's company, that changes an employee's feelings toward the company. We unpack our findings with illustrative quotations that indicate the presence of prosocial sensemaking and the process through which it links giving to affective commitment. ${ }^{1}$

As a preview, our findings suggest that the act of giving to the ESF cultivated affective organizational commitment by strengthening employees' perceptions of both personal and company prosocial identities_-images of the self and the organization as helpful, caring, and benevolent (Grant, 2007; see also Mayer, Davis, \& Schoorman, 1995). First, at a personal level, when employees gave to the ESF, they engaged in prosocial sensemaking about the self: they interpreted their contributions as caring, and then generalized this interpretation to their self-concepts, reinforcing their prosocial identities as caring individuals. As a result of gratitude to the company for the opportunity to affirm a valued aspect of their identities, they developed stronger affective commitment to the company. Second, at a company level, when employees gave to the ESF, they engaged in prosocial sensemaking about the company: they judged the company's contributions as caring, and then generalized this interpretation to their views of the company, reinforcing the company's prosocial identity as a caring organization. As a result of pride in the company as a humane organization, they developed stronger affective commitment to the company. In the following sections, we present testable hypotheses that elaborate how this prosocial sensemaking process unfolds to link giving and commitment through both personal and company pathways.

\section{Prosocial Sensemaking about the Self}

Our data suggest that giving to the ESF strengthened affective organizational commitment by triggering prosocial sensemaking about the self-a process through which employees interpreted their personal actions and identities in more caring terms. In contrast to the dominant construction of

\footnotetext{
${ }^{1}$ Although our theory-building efforts drew heavily on both manager and associate interviews, our quotations focus primarily on managers because, compared to associates, they tended to have more experience with giving to the ESF, and thus offered richer responses for illustrating the themes that inform our hypotheses. We balance this limitation in Study 2, where our sample is comprised of over 80 percent associates and we measure job level (manager vs. associate) as a control variable.
}

corporate life as self-interested (Miller, 1999), giving to the ESF provided employees with an opportunity to interpret their actions as caring. The company legitimated concern for others by formalizing and institutionalizing an employee support program, signaling that helping, giving, and contributing behaviors are valid, acceptable, and encouraged. As one manager explained, "Donating myself [helps me to see that] business can make you very focused on [making] money, and this kind of releases you from that, to think about other people, to reach out to others in need" (manager 7). An associate elaborated, "I have money taken out every paycheck to help with the ESF . . . it benefits a lot of people that really are in need.... I feel real good that it's available. I feel good that it can be taken out of my paycheck" (associate 16).

Employees discussed how they had often felt motivated to help coworkers and give their time and energy to the company, but lacked an appropriate means for doing so, as well as a compelling explanation for why they would do so. They felt that the ESF provided them with both a means and a rationale: they were able to give money to the ESF as part of regular donation campaigns and payroll deductions, and they were able to explain this giving behavior as part of a legitimate standard practice. Employees were also able to give time to the ESF as part of their roles as concerned managers and associates. For example, a manager described how the ESF provided her with the ability to help an employee in need:

I have an employee ... she was a young single mother.... During the pregnancy, she switched from full-time to part-time, and in the process lost her insurance because she didn't read the packet completely.... . When we found out, I grabbed the ESF paperwork and started calling the ESF, and it was just the ability to help her through her pregnancy.... It was good that there was somebody there that I could call and say, "Hey, this is what I've got, and can I help?" and to know that I was going to be able to help my employee.... Because of the help that they've been to the employees ... I feel good, because I know that there's somebody out there that it's helping. (manager 11)

As a result of judging their contributions as caring, employees were able to generalize these interpretations to reinforce their prosocial identities. They made sense of who they were through what they did (Bem, 1972; Weick, 1995), coming to see themselves as caring, helpful individuals. Employees discussed how the act of giving time and money to the ESF reinforced their prosocial identities by enabling them to contribute more than they could have on their own. They appreciated the steps that 
the company took to match and extend their financial contributions in order to help others in need. For example, one manager spoke about how giving to the ESF reinforced her prosocial identity as a caring person by expanding the impact of her donations on coworkers in New Orleans affected by Hurricane Katrina in August 2005:

I'm a pretty caring person . . . it's important for me to get involved in my staff's lives. . . . During the Hurricane Katrina relief, my partner and I discussed it and decided that, you know, that would be something we did, because then . . . people we knew were gonna be helped. . . . Feeling that I could give my hundred dollars to the ESF, they turned it into two hundred dollars, and then they helped fellow employees. You know, they got them jobs elsewhere. They ... helped them get back into their homes. They were able to do small things that meant a lot to those people ... it's better than I could've done myself. I wasn't gonna be able to go down there and help, so that's how I contribute. I wanted to help out ... my money essentially was doubled.... I feel like I've done something good. . . . I've spent my money in a smart way, knowing that it's gonna be matched. You know, I think that's really an important thing, not just that the ESF collects everyone else's money, but also that there's the matching factor in there, so it makes me feel like what I donate can go further. And, you know, that it's administered in such a way that they're not gonna be taken advantage of, and that they're gonna be very good help to someone at a very specific time. I always feel good when I do it. . . . Any time I do stop to give it some thought, I think things like ... "It's a good thing that I'm a part of this," and, you know, "This really is a good thing that my company has." (manager 4)

Another manager described how giving led him to include caring actions as part of his role on the job, which affirmed his identity as someone who helped others:

It's my job, too, to raise the awareness ... that we have this great ESF. I think that's my role now. ... I am involved as a company spokesperson on my store, being a leader, letting people know that it's available. ... I have a payroll deduction and then I also did the extra one for the Katrina Fund. I also have bought some items that they have sold, T-shirts to give to the staff, that I know a percentage of the proceeds went to the ESF. So those are ways that I can think of that I've helped. ... I think it's good to give. (manager 12)

Our understanding of the process of prosocial sensemaking about the self is based on theories of self-affirmation and self-verification, which suggest that employees are motivated to reinforce and authenticate valued aspects of their identities
(Shamir, 1990; Swann, Polzer, Seyle, \& Ko, 2004). As we illustrate below, employees felt grateful to the company for providing an opportunity to reinforce their prosocial identities through giving, and this gratitude to the company strengthened their affective commitment to the company. In the language of attribution theory (Weiner, 1985), employees attributed the opportunity to reinforce their prosocial identities to the company, and became more committed to the company as a result. For example, an associate explained how the company strengthened her attachment by providing her with a way to donate to Katrina victims through the ESF, reinforcing her prosocial identity as a giving person: "We raised money and raised money with the Katrina disaster. ... It makes you feel good to try and help other people.... I didn't even have to think about it. People needed help; they were offering a way to help send money and do something to help them ... it's good for morale, for the way people feel about the company that they work for" (associate 10).

Thus, giving to the ESF enabled employees to judge their actions and identities in more prosocial, caring terms. By providing the opportunity to engage in giving behavior, the ESF qualified otherinterested behavior as normal and accepted and provided employees with means and rationales for giving. Employees experienced the opportunity to give as a psychological benefit provided by the company. As predicted in social exchange theory (Blau, 1964), employees reciprocated by strengthening their affective commitment to the company. Our qualitative data thereby uncover a process of prosocial sensemaking about the self that helps to explain the giving-commitment relationship. We capture this process in the following set of hypotheses:

Hypothesis 1a. The higher an employee's level of giving to a support program, the greater the employee's interpretations of personal actions as caring.

Hypothesis $1 b$. The greater an employee's interpretations of personal actions as caring, the stronger the employee's personal prosocial identity.

Hypothesis 1c. The stronger an employee's personal prosocial identity, the higher the employee's level of affective commitment to the company.

Hypothesis 1d. Prosocial sensemaking about the self (judging personal actions and identities as caring) partially mediates the association between giving and affective commitment. 


\section{Prosocial Sensemaking about the Company}

Giving to the ESF also strengthened affective organizational commitment by triggering prosocial sensemaking about the company-a process through which employees interpreted the company's actions and identity in more caring terms. Our data suggest that giving to the ESF counteracted employees' skepticism about the company's intentions by increasing employees' awareness of the company's efforts to do good. Some employees were cynical about the company's motives, perhaps because the company is situated in the retail industry and accordingly tends to offer low monetary compensation. However, through giving, employees observed the company's efforts to match their contributions and encountered stories about how the funds were being utilized to help employees in need. Employees explained that through giving to the ESF, they encountered firsthand evidence that the company was taking action to help its people, which enabled them to see the company's actions as caring. For example, one manager described how contributing to the ESF's efforts to donate bereavement baskets to employees who lost family members led her to interpret the company's actions as family-oriented: "We support each other . . . a couple of employees who had lost family members got gift baskets because I called the ESF to let them know about it. ... It gives that sense of caring from the company, that sense of, you know, we're there to help you out in your times of need, that sense of family" (manager 11). Another manager said, "This ESF thing is a great example of trying to keep it a family. ... It made me feel good to know that the money that I give out of my paycheck, well, it primarily goes to help someone ... within this company" (manager 5).

Giving to the ESF provided employees with repeated exposure to the company's caring actions, enabling employees to generalize these actions to the company's identity as a caring, humane organization. As one associate explained, "It's given me a little bit of faith in our corporate structure that I didn't have before.... [In] major corporations today ... it's all about the bottom line.... I understand that way of thinking, but, you know, it's always nice to . . . break out of that and, you know, add a little bit of heart" (associate 8). Another manager elaborated on how giving and contributing to these humane efforts bolsters employees' confidence that the motives behind the ESF were genuine and benevolent:

I have had, during my time as general manager, about three employees that I've put in contact with the ESF for emergency assistance. Yeah, I've had one employee who was having a lot of medical issues that were impacting his ability to work, and therefore to, you know, pay his bills and things like that. ... I was able to put him in touch with the ESF to ask for additional assistance. I know another ... person who got help through an unexpected pregnancy and ... financial stress relating to that, and they helped her out as well. And so I think it's a really neat program for the company to have. It's one of those things that highlights to me the fact that this company really does care about their employees. (manager 6)

Our understanding of the process of prosocial sensemaking about the company draws on theory and research on corporate social responsibility and organizational compassion, which suggest that employees are attracted to, and take pride in, organizations that aim to do good (Bansal, 2003; Lilius et al., 2008; Turban \& Greening, 1997). As a result of seeing the company's identity in more prosocial terms, employees experienced greater pride in the company, and thereby felt more affectively committed to it. For instance, an associate who made regular financial donations to the ESF explained that giving strengthened her feelings of pride in being part of a caring company:

I do feel very attached to the company. ... I always feel proud that the company [supports the ESF], and ... I think my money's being put to very good use. So I'm always happy to do it. I think companies should give back.... I feel proud that our company does that ... and is in that kind of space where they're like, you know, let's give back. Let's help others. So it does make me feel proud that, you know, my company does that. (associate 11)

Similarly, a manager discussed how the experience of giving to the ESF solidified her affective commitment to the company by enabling her to see the company in caring, humane terms: "The fact that the ESF exists is something that impresses me about the company.... I just think it's a good, humanitarian effort. . . . I'm proud that I can say I work for a company that has something like this ... it kind of makes it a little more personal for me" (manager 4). Three other managers who gave to the ESF expressed parallel sentiments:

It just makes [the company] kinder in my eyes. . . . They recognize that there's a need, and that they've done something about it. . . It was very generous of them to even think of putting it together, to go out of their way to develop it. . . . How attached do I feel to the company? Very attached. (manager 7)

It makes you feel good that you work for a company that chooses to do something like this, that has something available for its employees.... I have a 
sense of pride in the company. ... I think it's good to give and, you know, it definitely makes me feel ... that I'm working for a company that shares in some of my sensibilities and cares about people. (manager 12)

Its fundamental purpose is to help any employee of Big Retail to alleviate the difficulties that they face when they're in a catastrophic situation. . . . I think it's important because I think it really reflects a kind of set of core values that the company has ... if you're trying to put something concrete on what makes Big Retail a compassionate company, or a caring company ... the ESF is something concrete that really reflects that. . . . I believe that Big Retail really sets the bar for what a good company is to work for ... that's the fundamental [basis] of my strong attachment to Big Retail. (manager 1)

Thus, giving to the ESF enabled employees to judge the company's actions and identity in more prosocial, caring terms. By exposing employees to the company's efforts to do good, giving counteracted common skepticism about the company's intentions and motives, strengthening employees' affective commitment to the company by cultivating feelings of pride in the company. We capture the process through which prosocial sensemaking about the company explains the giving-commitment relationship in the following set of hypotheses:

Hypothesis 2a. The higher an employee's level of giving to a support program, the greater the employee's interpretations of company actions as caring.

Hypothesis 2b. The greater an employee's interpretations of a company's actions as caring, the stronger the company's prosocial identity.

Hypothesis 2c. The stronger a company's prosocial identity, the higher an employee's level of affective commitment to the company.

Hypothesis 2d. Prosocial sensemaking about a company (judging company actions and identities as caring) partially mediates the association between giving and affective commitment.

\section{STUDY 1 DISCUSSION}

Our emergent model suggests that giving to Big Retail's ESF strengthens affective commitment to the company by triggering prosocial sensemaking about the self and the company. Giving enables employees to see personal and company actions and identities in more caring terms, resulting in increased affective commitment to the company. Having used qualitative data to identify these prosocial sensemaking processes, we sought to con- duct an exploratory quantitative investigation of their ability to explain the relationship between giving and commitment.

\section{STUDY 2 METHODS}

We collected survey data from Big Retail employees that allowed us to provisionally test the model depicted in Figure 1. Our objective was to lend further grounded support, using a different sample and quantitative rather than qualitative data, to our Study 1 hypotheses.

\section{Sample}

We collected surveys from 249 employees at Big Retail in July 2006. Sixty-eight percent of the respondents were female; their mean age was 29.08 years (s.d. $=2.50$ years), and their mean tenure at the company was 5.52 months (s.d. = 3.83 months). The company operated several hundred retail stores throughout the United States, and 3,000 participants were asked to volunteer to complete an anonymous web survey about the ESF and their feelings about the company. As an incentive to participate, participants were offered entry into a drawing to win a $\$ 1,000$ gift certificate redeemable at any Disney resort, park, or store. Potential respondents were selected by a computer generator that randomly drew employee identification numbers.

Company policies prohibited the use of many standard response facilitation approaches, including prenotifying, publicizing, sending reminder notes, providing multiple response formats, monitoring survey response, and fostering survey commitment (Rogelberg \& Stanton, 2007). Employees were not given time to complete the survey at work, and because many of the stores were undergoing changes in physical layout, HR managers informed us that it was likely that a substantial proportion of the 3,000 mailings had failed to reach potential respondents. Nevertheless, since the response rate of 8.3 percent was quite low, we undertook several steps recommended by Rogelberg and Stanton (2007) to assess nonresponse biases. First, we conducted an archival analysis comparing respondents with the total Big Retail employee population on available demographic data. Proportions of respondents were quite similar to the population in terms of job level, gender, tenure, and age (see Table 1). The distribution of respondents also matched the total employee population in terms of geographic locations. Thus, the sample appeared to be representative on demographic dimensions. In addition, the proportion of Big Retail's population that had donated to the ESF $(56.0 \%)$ nearly perfectly matched the proportion of 
TABLE 1

Study 2 Nonresponse Bias Impact Assessment

\section{(a) Archival Analysis}

Category

Job level: Manager

Job level: Associate

Gender: Male

Gender: Female

Tenure: $0-1$ years

Tenure: $1-3$ years

Tenure: $3-5$ years

Tenure: $5+$ years

Age: $25-34$

Age: $35-44$

Age: $45-54$

Age: $55-64$

Giving behavior: Has donated to the ESF

Giving behavior: Has not donated to the ESF
Big Retail Population

Respondent Sample

$19.6 \%$
82.8
41.0
59.0
35.8
24.2
12.4
28.5
25.4
17.2
12.5
7.4
56.0
44.0

$19.4 \%$

80.6

33.5

66.5

25.4

24.2

16.5

33.9

25.2

24.0

12.4

11.2

56.1

43.9

(b) Wave Analysis ${ }^{a}$

\begin{tabular}{|c|c|c|c|c|}
\hline Variable & Day 1-3 (23\%) & Day 4-6 (30\%) & Day $7-9(21 \%)$ & Day $10+(26 \%)$ \\
\hline $\begin{array}{l}\text { Interpretations of personal ESF } \\
\text { contributions as caring }\end{array}$ & $0.34 \quad(0.48)$ & $0.32(0.45)$ & $0.33 \quad(0.53)$ & $0.41 \quad(0.53)$ \\
\hline $\begin{array}{l}\text { Interpretations of company ESF } \\
\text { contributions as caring }\end{array}$ & $0.64 \quad(0.75)$ & $0.55 \quad(0.64)$ & $0.48 \quad(0.61)$ & $0.41 \quad(0.64)$ \\
\hline Personal prosocial identity & $5.99 \quad(0.80)$ & $5.95 \quad(0.84)$ & $6.11 \quad(0.61)$ & $5.81 \quad(0.86)$ \\
\hline Job satisfaction & $5.22 \quad(1.46)$ & $5.14 \quad(1.69)$ & $5.69(1.25)$ & $5.27(1.54)$ \\
\hline Anticipation of receiving ESF support & $1.01 \quad(0.77)$ & $0.94 \quad(0.76)$ & $0.91 \quad(0.74)$ & $0.94 \quad(0.77)$ \\
\hline Past ESF support received & $0.11 \quad(0.36)$ & $0.11 \quad(0.31)$ & $0.02 \quad(0.14)$ & $0.14 \quad(0.39)$ \\
\hline Age & $38.64(13.24)$ & $36.25(13.32)$ & $36.22(12.78)$ & $35.47(14.00)$ \\
\hline Company tenure & $5.36 \quad(5.25)$ & $4.44 \quad(4.75)$ & $3.94 \quad(4.38)$ & $5.30 \quad(5.20)$ \\
\hline Job level & $0.14 \quad(0.35)$ & $0.15 \quad(0.36)$ & $0.21 \quad(0.41)$ & $0.28 \quad(0.45)$ \\
\hline
\end{tabular}

a The wave analysis shows variable means by response category, with standard deviations in parentheses. Scheffé's multiple comparison test showed no statistically significant differences between any of the day categories on any of the measured variables.

our respondents that had donated to the ESF (56.1\%). This evidence minimizes the concern that employees who gave to the ESF would have been more likely to respond to the survey, suggesting that we have sufficient (and representative) variance on our independent variable of giving behavior. ${ }^{2}$

Second, we conducted a wave analysis comparing early to late respondents, finding no significant

\footnotetext{
${ }^{2}$ We were also concerned that employees who were familiar with the ESF may have been more likely to respond. To assess this concern, two independent coders rated participants' responses to an open-ended question at the start of the survey: "To the best of your knowledge, what services does the ESF provide?" The two coders demonstrated 100 percent agreement, and the resulting data indicated that 18.5 percent of respondents had never heard of the ESF. This suggests that we received a reasonable response from employees who were unfamiliar with the ESF.
}

differences between early and late respondents on the measured variables (see Table 1). This finding does not conclusively rule out the possibility of response bias, but it decreases its likelihood by suggesting that responsiveness was not influenced by the variables being investigated (Rogelberg \& Stanton, 2007). Together, although these steps can only reduce but not eliminate concerns about response biases, they suggest that the sample is sufficiently representative of the population on key demographic and ESF dimensions-and that there is sufficient variance in the variables of interest-to warrant an exploratory test of our model.

\section{Measures}

Unless otherwise indicated, all items used a sevenpoint Likert-type response scale anchored at 1 "disagree strongly," to 7, "agree strongly". 
Affective commitment to the company (self-report). We measured affective commitment to the company with five of the six items from the affective commitment scale reported by Meyer, Smith, and Allen (1993), which includes items such as "I really feel as if this company's problems are my own" and "This organization has a great deal of personal meaning for me" $(\alpha=.94)$. We excluded the item "I would be very happy to spend the rest of my career with this organization" because this item reflects "turnover intentions" rather than the attitude or feeling of affective commitment to the organization (Pittinsky \& Shih, 2004).

ESF giving behavior (self-report). We measured ESF giving behavior with two items developed in collaboration with ESF managers. The first item asked employees if they had ever donated from their paycheck to the ESF and if they had ever volunteered for ESF fundraising campaigns (0, "neither"; 1, "yes to one"; 2 , "yes to both"). The second item asked them to indicate their agreement with the statement, "I donate to the ESF on a regular basis" ( $\alpha=.74)$.

Interpretations of personal and company ESF contributions as caring (independent coders). To measure employees' interpretations of personal and company ESF contributions as caring, we enlisted two independent coders. The coders rated employees' qualitative responses to four openended questions in the survey: "In a few sentences, please describe what the ESF means to you," "In a few sentences, please describe what you think the ESF means to the company," [for those who donate] "What are the reasons that you donate to the ESF?" and "What do you see as the strengths of the ESF?" The two coders rated whether or not each response from employees mentioned (1) their own contributions to the ESF as caring and/or (2) the company's contributions to the ESF as caring. Statements were coded as caring when they described personal or company actions as "generous," "benevolent," "good," "humane," "concerned," "compassionate," "having heart," or "intending to help." Table 2 displays sample statements for each of the two categories. We summed the ratings for each coder into an overall score for each employee, representing a count of the number of times $(0-4)$ that each employee mentioned interpreting personal and company contributions, respectively, as caring. These scores provided us with measures from a different source, using a different rating method than the self-report data. The coders demonstrated strong agreement. Using a two-way mixed model with consistency agreement, the intraclass correlation coefficients (ICCs) for personal ESF contributions were .62 $(p<.001)$ for single-measure reliability and $.77(p<.001)$ for average-measure reliability, and the ICCs for company ESF contributions were $.61(p<.001)$ for single-measure reliability and .76 $(p<.001)$ for average-measure reliability.

Personal prosocial identity and company prosocial identity (self-report). Drawing on commonly used phrases in our interview data, we developed three items each to measure employees' perceptions of their own prosocial identities and the company's prosocial identity. The items for personal prosocial identity were "I see myself as caring," "I see myself as generous," and "I regularly go out of my way to help others" $(\alpha=.84)$. The items for company prosocial identity were "I see this company as caring," "I think that this company is generous," and "I see this company as being genuinely concerned about its employees" $(\alpha=.94)$.

Control variable 1: Job satisfaction (selfreport). Because job satisfaction is strongly related to affective organizational commitment (Harrison, Newman, \& Roth, 2006; Mathieu \& Zajac, 1990), and also because common method and source biases were potential concerns, we measured job satisfaction as a control variable. Job satisfaction reflects general positive attitudes toward one's work and thereby serves as a filter through which other work judgments are made (Brief \& Weiss, 2002). We thus expected that controlling for job satisfaction would allow us to more rigorously assess the relationships among the constructs by adjusting these relationships for general positive attitudes (Podsakoff, MacKenzie, \& Lee, 2003). We used the job satisfaction scale developed by Quinn and Shepard (1974), which includes items such as "All in all, I am very satisfied with my current job" $(\alpha=.92)$.

Control variable 2: Anticipation of receiving ESF support (independent coders). Because anticipating support from the ESF might influence affective organizational commitment, we again enlisted two independent coders to rate employees' responses to the four open-ended questions about the ESF listed above. The two coders rated whether or not each response from employees mentioned that the ESF might provide them with support in the future; Table 2 provides sample statements. We summed the ratings for each coder into an overall score for each employee, representing a count of the number of times $(0-4)$ that each employee mentioned the possibility of receiving support from the ESF in the future. The coders once again demonstrated strong agreement. In a two-way mixed model with consistency agreement, the ICCs were $.52(p<.001)$ for single-measure reliability and .68 $(p<.001)$ for average-measure reliability. 
TABLE 2

\section{Study 2 Sample Statements for Coding Categories}

Interpretations of Personal ESF Contributions as Caring
Interpretations of Company ESF

Contributions as Caring
Anticipation of Receiving ESF Support
I feel a sense of goodness by doing so.

I donate what I can . . . I care about creating a sense of community and looking out for others. So I give what I am able to.

It makes me feel good knowing that I am able to help a fellow employee get back on their feet.

I donate as a way to help others who might be less fortunate than I.

I like to know that I had a small part of helping someone else out when needed.

I donate because I want to be a blessing to others.

I donate because every dollar makes a difference. It's a good cause.

I like helping employees who are in need.

In order for the ESF to continue to help others there must be people that can contribute. I feel that I am a person who will give as much as I can.

I appreciate the opportunity to contribute through my paycheck to those fellow employees in need.

I like helping others.

It's nice to feel that we can contribute.

Helps those employees who donate feel good about themselves/feel they are doing something useful.

Employee contributions give us a feeling of being directly involved in helping each other.

It makes people feel good to donate.

It's nice to feel that I'm contributing to something.

Gives employees an opportunity to think of and help each other.

Helping someone in need makes people feel good. It makes people feel as though something they did matters.
It's a great way to show my employees that not only do I care about them, but their company cares about them. When Big Retail helps one of my employees it reminds me that I work for a great company.

It helps to build a community for Big Retail employees and shows that the company cares about its employees.

I'm proud to work for a company that has taken the time and resources to form an ESF to help people in need.

I think it means it cares for employees. What this program does demonstrates the value the company states it feels for employees.

It gives the employees a better outlook toward the company. It seems like more than a cold business.

It shows that the company cares about its employees.

It's a way to show the human side of business. It's an extra arm that can reach out and give comfort when people need it most.

It strengthens employee loyalty. It humanizes the public image of the corporation.

I think it shows that Big Retail cares and looks out for its employees.

The ESF represents a commitment of caring and concern toward all employees.

It is a way for the company to show its concern for its employees.

It puts a more human face on a corporation. It means the company cares.

Helping employees through difficult times shows that a large company has a heart.

It makes you feel good to work for a company who helps its employees through tough times.
I know if I need financial assistance due to a life changing event, the ESF may be able to help me.

I feel secure they are there. If I ever need assistance, I know they are a stepping stone for me to go to for help.

It's nice to know in a worst case scenario that it's there-a safety net for some of the things benefits doesn't cover.

Having been a recipient several years ago, I can honestly say the ESF means there may be help available. It's kind of like a friend . . . it's nice to know they're here.

It means that if something were to happen to me such as a death in the immediate family, I can ask for help. Also may help with college expenses.

The ESF gives us all the assurance that should something arise with a significant financial impact that we are unable to handle on our own, we will have a partner in the company to deal with the situation ... the company is willing to invest in our lives.

If I need financial assistance, I can apply for a grant.

I have heard the ESF would provide financial aid for school. I . . . would like to take advantage [of this] in the future.

If I am ever in need of its assistance I will take advantage of it.

A service that issues grants to Big Retail employees who truly are in need [is] one that I may need to take advantage of someday.

I hope to benefit from it with a scholarship stipend for my children in the future.

\section{Control variable 3: Past ESF support received} (self-report). Because having received support from the ESF in the past could also influence affective organizational commitment, we asked employees to report whether they had ever received assistance from the ESF (0, "never"; 1, "once"; 2, "twice").

Control variables 4-6: Demographic characteristics. In their seminal meta-analysis, Mathieu and Zajac (1990) examined a number of demographic correlates of organizational commitment, finding that the three strongest demographic correlates were age, organizational tenure, and job level. Accordingly, we asked employees to report their age (years), company tenure (years), and job level (1, "managerial role"; 0, "associate”).

\section{STUDY 2 RESULTS}

Because the sample was sufficient in size and respondent-to-item ratio, we analyzed the data with structural equation modeling (SEM), using EQS software (version 6.1) with maximum likelihood estimation procedures. Missing data was not a significant problem, as all items had less than 3 percent of cases missing. Following recommendations from Anderson and Gerbing (1988), we began by conducting a confirmatory factor analysis specifying a 12 -factor solution, which displayed excellent fit with the data according to the rules of thumb in the literature ( $\mathrm{Hu} \&$ Bentler, 1999) $\left(\chi^{2}\right.$ $[237]=345.83$, NNFI $=.96, \mathrm{CFI}=.97$, RMSEA $=$ .04 , RMSEA confidence interval $=.03, .05)$. Factor 
TABLE 3

Study 2 Means, Standard Deviations, and Disattenuated Correlations at the Index Level ${ }^{\mathrm{a}}$

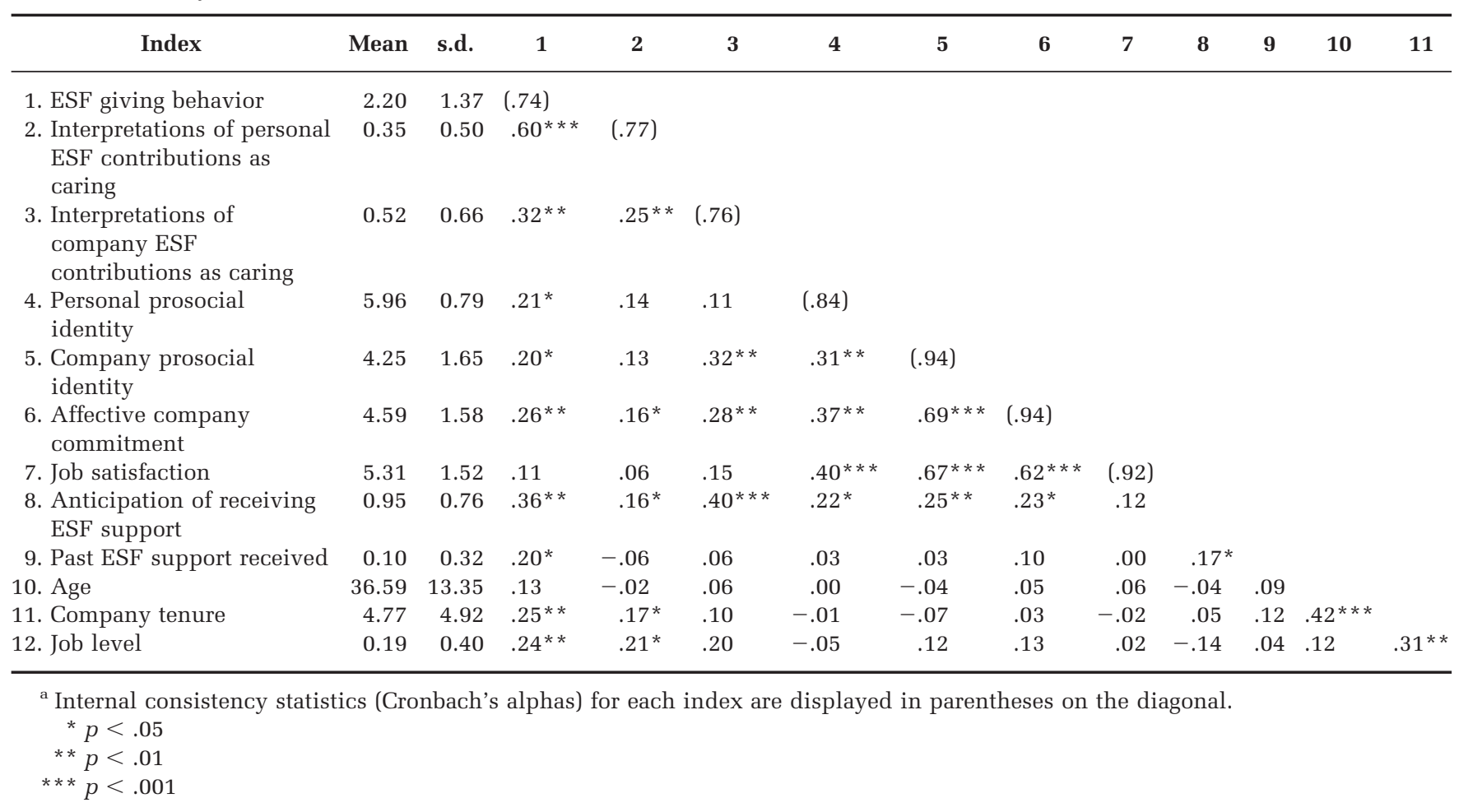

correlations, along with means and standard deviations, are displayed in Table 3.

To examine whether this was the most parsimonious solution, we compared this 12 -factor model with two plausible alternative models. The correlations in Table 3 indicate four high correlations: ESF giving behavior and interpretations of personal ESF contributions as caring (F1 and F2; $r=.60$ ), company prosocial identity and affective commitment (F5 and F6; $r=.69$ ), prosocial company identity and job satisfaction (F5 and F7; $r=.67$ ), and affective commitment and job satisfaction (F6 and F7; $r=.62$ ). These correlations suggest two plausible alternative models. The first, an 11-factor model with ESF giving behavior and interpretations of personal ESF contributions as caring loading on the same factor, displayed poorer fit on all indices $\left(\chi^{2}\right.$ $[248]=444.30, \mathrm{NNFI}=.93, \mathrm{CFI}=.95, \mathrm{RMSEA}=$ .06 , RMSEA confidence interval $=.05, .07)$. A chisquare difference test showed that the fit of the 12 -factor model was significantly superior to that of this alternative model $\left(\chi^{2}[11]=98.47, p<.001\right)$. The second, a ten-factor model with prosocial company identity, affective commitment, and job satisfaction loading on a single factor, displayed very poor fit on all indices $\left(\chi^{2}[258]=1062.91\right.$, NNFI $=$ $.72, \mathrm{CFI}=.78$, RMSEA $=.12$, RMSEA confidence interval $=.11, .12$ ). A chi-square difference test showed that the fit of the 12 -factor model was sig- nificantly superior to that of this alternative model $\left(\chi^{2}[19]=717.08, p<.001\right)$. Thus, the 12-factor model displayed significantly better fit than both of the plausible alternative models.

Structural models. We then tested full structural models both with and without control variables. The model without control variables (Figure 2) demonstrated excellent fit with the data according to $\mathrm{Hu}$ and Bentler's (1999) cut-off values $\left(\chi^{2}[111]=\right.$ 169.42, NNFI $=.97$, CFI $=.98$, RMSEA $=.05$, RMSEA confidence interval $=.03, .06) .{ }^{3}$ As depicted in Figure 3, the model still displayed good fit after we added the control variables as exoge-

\footnotetext{
${ }^{3}$ To examine the possibility of reverse causality, we tested an alternative model in which affective commitment led to giving behavior, which led to interpretations of personal and company ESF contributions as caring, which in turn led to personal and company prosocial identity. This model involved moving affective commitment from its position as the final dependent variable to a position as the only exogenous independent variable. On all indices, the model displayed poorer fit and failed to achieve $\mathrm{Hu}$ and Bentler's (1999) cutoff values: $\chi^{2}$ $(112)=288.11$, NNFI $=.92$, CFI $=.94$, RMSEA $=.08$, RMSEA confidence interval $=.07, .09$. A chi-square difference test demonstrated that our initial model displayed significantly superior fit to this alternative model: $\chi^{2}(1)=118.69, p<.001$.
} 
FIGURE 2

Study 2 Structural Model ${ }^{\mathrm{a}}$

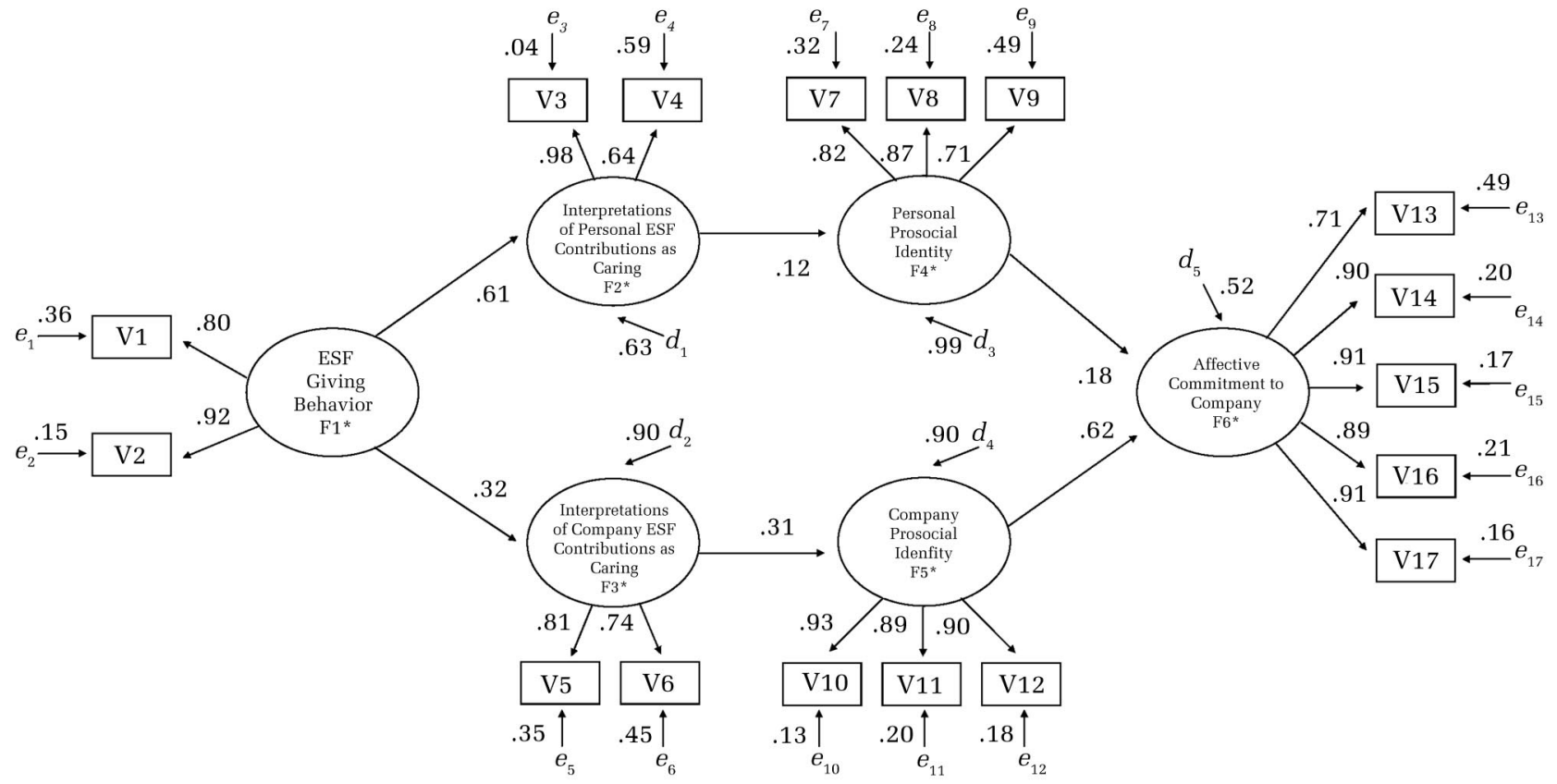

${ }^{\mathrm{a}} \chi^{2}(111)=169.42$, NNFI $=.97$, CFI $=.98$, RMSEA $=.05$, RMSEA confidence interval (.03, .06). All reported relationships are statistically significant at the $p<.05$ level. Asterisks indicate that the factor correlations are freely estimated.

The prosocial individual and company identity factors explained a total of 48 percent of the variance in affective organizational commitment. Because common causes may have been omitted, we allowed two residual disturbances to correlate freely: d1-d2 and d3- d4.

nous influences on affective commitment $\left(\chi^{2}\right.$ $[270]=548.86, \mathrm{NNFI}=.91, \mathrm{CFI}=.92, \mathrm{RMSEA}=$ .07 , RMSEA confidence interval $=.06, .08)$. In both models, supporting our hypotheses, there were statistically significant paths from ESF giving behavior to interpretations of personal ESF contributions as caring (Hypothesis 1a) to personal prosocial identity (Hypothesis $1 \mathrm{~b}$ ) to affective commitment (Hypothesis 1c), and from ESF giving behavior to interpretations of company ESF contributions as caring (Hypothesis 2a) to company prosocial identity (Hypothesis 2b) to affective commitment (Hypothesis 2c). ${ }^{4}$

Mediation analysis. The previous analyses demonstrated that the mediators were significantly related to both the independent and dependent variables. To examine whether the intervening variables mediated the relationship between giving

${ }^{4}$ To examine whether giving explained variance over and above the six control variables in predicting affective commitment, we conducted a hierarchical regression analysis. Even with all six control variables included, giving behavior was a significant predictor of affective commitment $(\beta=.14, t[239]=2.61, p=.01)$, increasing variance explained significantly (from $R^{2}=.40$ to $R^{2}=$ $.42, F[1,232]=6.81, p=.01)$. behavior and affective commitment to the company, we followed the procedures recommended by James, Mulaik, and Brett (2006). ${ }^{5}$ We estimated the indirect effects with the coefficients from the full model and then used bootstrapping methods to construct confidence intervals based on 1,000 random samples with replacement from the full sample (Stine, 1989). ${ }^{6}$ The coefficient for the prosocial

${ }^{5}$ We also examined whether the mediated paths improved model fit by testing a nested model in which we added a direct path from giving to commitment and removed the mediating prosocial sensemaking paths. Despite the decrease in parsimony, the mediated model displayed significantly superior fit $\left(\chi^{2}[1]=57.52, p<.001\right)$.

${ }^{6}$ Because this is a two-stage mediation model rather than a traditional one-stage mediation model, each indirect effect is the product of three paths $([\mathrm{F} 1 \rightarrow \mathrm{F} 2] \times$ $[\mathrm{F} 2 \rightarrow \mathrm{F} 4] \times[\mathrm{F} 4 \rightarrow \mathrm{F} 6]$ for prosocial sensemaking about the self and $[\mathrm{F} 1 \rightarrow \mathrm{F} 3] \times[\mathrm{F} 3 \rightarrow \mathrm{F} 5] \times[\mathrm{F} 5 \rightarrow \mathrm{F} 6]$ for prosocial sensemaking about the company), rather than the standard two paths. Accordingly, the path coefficients for the indirect effects are substantially lower than would be observed for a traditional one-stage mediation model. This is merely a scaling artifact of the standardized paths being represented on a scale from 0 to 1 . The standard errors are affected in the same direction, resulting in an accurate estimate of the confidence intervals. 
FIGURE 3

\section{Study 2 Structural Model with Control Variables ${ }^{\text {a }}$}

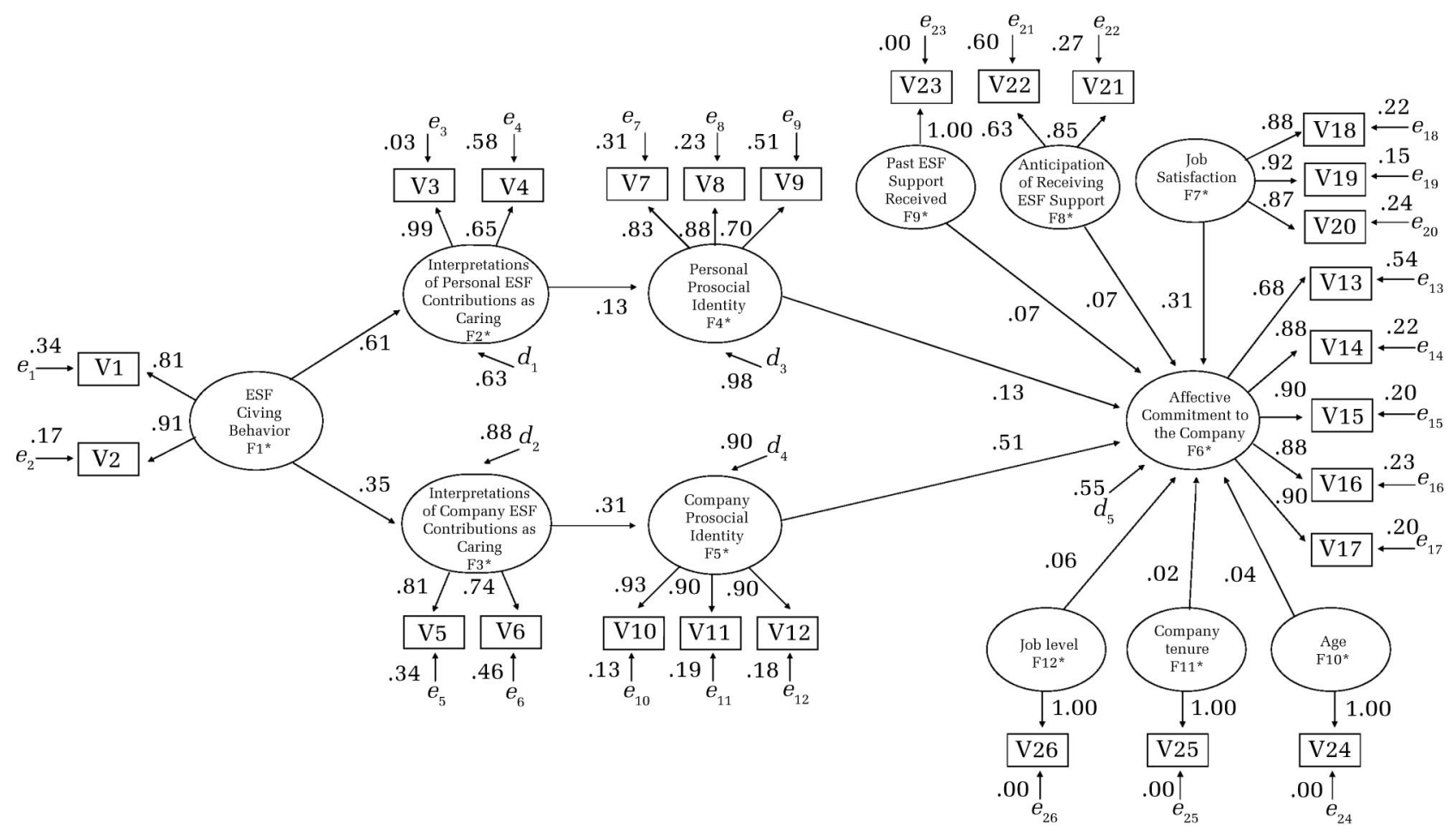

${ }^{\mathrm{a}} \chi^{2}(268)=533.08, \mathrm{NNFI}=.91, \mathrm{CFI}=.93, \mathrm{RMSEA}=.07, \mathrm{RMSEA}$ confidence interval $(.06, .07)$. All paths from the original model are statistically significant at the $p<.05$ level, but of the six control variables, only the path from job satisfaction was significant. We allowed ESF giving behavior to correlate freely with all of the control variables, which also correlated freely with each other.

sensemaking about the self path was .02, and the 95 percent confidence interval excluded zero $(.01, .02)$. The coefficient for the prosocial sensemaking about the company path was .07 , and the 95 percent confidence interval excluded zero $(.07, .08)$. Since mediation is present when the size of an indirect effect is significantly different from zero (Shrout \& Bolger, 2002), these confidence intervals suggest that each of the two pathways was a partial mediator: the link between giving to the ESF and affective commitment was partially mediated by prosocial sensemaking about the self (Hypothesis 1d) and prosocial sensemaking about the company (Hypothesis 2d).

\section{STUDY 2 DISCUSSION}

This provisional quantitative test provided support for our theoretical model. We found that giving behavior explained significant variance in affective organizational commitment, even after controlling for past support received from the ESF and expected future support received from the ESF, as well as job satisfaction, age, company tenure, and job level. We further found that each of the two prosocial sensemaking mechanisms identified in the qualitative study partially mediated the asso- ciation between giving and commitment. These findings suggest that giving to an employee support program is associated with higher levels of affective commitment to one's organization through employees' interpretations of personal and organizational actions and identities in prosocial, caring terms.

\section{GENERAL DISCUSSION}

We used qualitative and quantitative data to build and test theory about the relationship between giving to an employee support program and affective commitment to the organization that manages the program. Taken together, our findings suggest that giving triggers a process of prosocial sensemaking about the self and the company that strengthens employees' affective commitment to the company. The two studies provide convergent evidence for our claims that giving strengthens affective commitment by enabling employees to interpret personal and company actions in more caring, prosocial terms. Our findings extend previous research by introducing giving as a novel antecedent of commitment and as a novel, other-interested process through which employee support programs 
cultivate commitment. Our findings also extend previous research by identifying two prosocial sensemaking mechanisms through which giving cultivates commitment, drawing attention to the importance of prosocial interpretations of personal and organizational actions and identities as sources of commitment.

\section{Theoretical Implications}

Below, we elaborate on how our studies contribute to theory and research on organizational programs, commitment, sensemaking and identity, and citizenship behavior.

Organizational programs. Our research makes two contributions toward understanding the organizational and individual benefits of support programs. First, as noted earlier, scholars have traditionally assumed that support programs cultivate commitment through the self-interested pathway of enabling employees to receive support (e.g., Goodstein, 1995; Johnson, 1986; Trice \& Beyer, 1984). Our findings suggest that support programs also cultivate commitment through the other-interested pathway of enabling employees to give support. We thus provide researchers with a wider conceptual lens for examining how support programs assist organizations in increasing employee commitment by facilitating both giving and receiving. Second, with respect to individual benefits, scholars have focused primarily on the experiences of employees who receive support, giving less attention to the experiences of employees who provide support (Bacharach et al., 2000). Our findings underscore the potential benefits of support programs for support providers, in terms of seeing their personal identities and the company's identity in more prosocial, caring terms. Our findings bolster evidence that support can benefit givers as well as receivers (Penner, Dovidio, Piliavin, \& Schroeder, 2005). Our research thus provides scholars with a new window for investigating and understanding the organizational and individual benefits of support programs.

Our research also informs scholarship on the psychological processes through which a broader class of organizational programs, not only support programs, cultivates commitment. The prosocial sensemaking process that we proposed is applicable to any organizational program that provides employees with opportunities to give and contribute, including corporate volunteer programs and corporate social responsibility initiatives. Whereas scholars often understand these programs as providing image benefits to organizations (e.g., Elsbach, 2003), our research suggests that these pro- grams can enable employees to contribute to, and thus attach to, the organizations. Our research suggests that by providing opportunities to give, organizational programs can facilitate employees' efforts to construct prosocial identities as caring individuals, as well as to see their organization as a more prosocial, caring institution. These findings are applicable to a wide variety of programs in which an organization provides a valued giving opportunity: when employees act on the opportunity to give, they are able to see themselves and the organization as more caring, which is likely to strengthen their commitment to the organization that manages the program.

Commitment. Our research answers recent calls to explain commitment using alternative theoretical mechanisms that transcend self-interest (Meglino \& Korsgaard, 2004). We find that behaviors directed toward giving and contributing can strengthen employees' emotional bonds with their work organizations. Our discovery of prosocial sensemaking processes suggests that affective commitment can be shaped in powerful ways by prosocial interpretations of the self and the organization as caring entities, advancing existing theory toward a more complete understanding of the antecedents of affective organizational commitment. Indeed, in their meta-analysis, Meyer et al. (2002) found that work experiences in which employees receive positive treatment from an organization-in the form of perceived organizational support, transformational leadership, organizational justice, and clearly defined, well-structured rolesare the strongest known predictor of affective organizational commitment. Our research suggests that in addition to the treatment that employees receive from the organization, the giving behaviors in which employees engage toward the organization have important implications for their affective commitment to the organization.

Our research further fills a gap in existing knowledge about the role of emotions in affective organizational commitment. Although affective organizational commitment is by definition an emotion-laden attitude, little research has examined the role of discrete emotions in guiding this commitment (e.g., Brief \& Weiss, 2002). Although we were unable to test these mechanisms in our quantitative model, our qualitative findings shed light on the relationship between the discrete emotions of gratitude and pride and affective commitment. Our results suggest that when employees engage in prosocial sensemaking about the self, their commitment is based on gratitude to their organization for facilitating their own giving behaviors and caring identities. When employees engage in prosocial sensemaking about the organization, their 
commitment is based on pride in the organization for being a giving and caring institution. These findings illuminate how giving can foster commitment through two distinct emotional pathways.

Sensemaking and identity. Our research adds novel content to the traditionally process-focused theories of sensemaking and identity. Sensemaking theories emphasize the processes through which individuals interpret actions and identities, paying less attention to the content of these interpretations - the type or nature of understandings formed (Maitlis, 2005; Pratt, 2000; Weick, 1995; Weick, Sutcliffe, \& Obstfeld, 2005). Similarly, identity theories emphasize the processes through which individuals develop and maintain personal and collective self-concepts (e.g., Dutton, Dukerich, \& Harquail, 1994), giving less attention to the content of these self-concepts-the descriptive adjectives that characterize the identity (Wrzesniewski, Dutton, \& Debebe, 2003). Our research points to the importance of other-interested, prosocial content in employees' sensemaking and identity construction efforts. It also highlights that sensemaking is more than a cognitive process, generating and being affected by the emotions of gratitude and pride that prosocial sensemaking evokes.

Citizenship behavior. Our research enriches existing knowledge about organizational citizenship behavior, acts directed toward contributing to other people and an organization. Research has demonstrated that affective organizational commitment is a robust predictor of citizenship behaviors (Harrison et al., 2006; Meyer et al., 2002). Our research reverses the causal arrow by suggesting that citizenship behaviors are not only influenced by, but can also strengthen, organizational commitment. By contributing to their organization, employees are internally and externally signaling their investment in the organization, creating private and public conditions for enhanced commitment. Our research thus enters the long-standing debate about whether attitudes cause behaviors and/or vice versa. Although there is now clear evidence that causality flows in both directions (e.g., Judge, Thoresen, Bono, \& Patton, 2001; McBroom \& Reed, 1992), researchers have primarily assumed that behaviors are a consequence of affective commitment, paying little attention to the possibility that behaviors are also a cause of affective commitment (see Meyer et al., 2002). We have taken a step toward balancing this literature by suggesting that giving behaviors can cause, not only result from, affective organizational commitment. Our research thereby identifies fresh questions for researchers to investigate concerning how the act of contributing shapes employees' organizational commitment.
Our research also advances this literature by shedding new light on the motives that underlie citizenship behavior. Organizational scholars have debated about whether citizenship behavior is driven by self-interested or prosocial motives (Bolino, 1999; Meglino \& Korsgaard, 2004), and our findings suggest that this debate contributes to a false dichotomy. Rather than pitting self-interested and prosocial motives against each other, our findings suggest that giving can serve both sets of motives simultaneously. We find that organizations' efforts to facilitate the experience of giving and contributing to a support program indirectly serve employees' self-interests by enabling them to see themselves and the company in more prosocial, caring terms. Our research thereby answers recent calls to explain attitudes and behaviors through theoretical perspectives that blend, rather than dichotomize, self-interest and other-interest (De Dreu, 2006; Grant, 2007).

\section{Managerial Implications}

Our findings suggest that managers can achieve both individual and organizational benefits by providing employees with opportunities to give and contribute. This advice to managers is somewhat counterintuitive: we propose that organizations can cultivate commitment not only by enabling employees to receive support, but also by enabling employees to give support. By designing programs that enable employees to help others, managers may improve the quality of employees' experiences while simultaneously promoting the welfare of recipients and benefiting from increased affective commitment from employees. Our findings may motivate managers to achieve these benefits by engaging in the following specific behaviors: (1) introducing employee support programs, (2) designing these programs to allow employees to give as well as receive, (3) communicating to employees about the range of ways in which they can give time and money to these programs, (4) dismantling norms of self-interest by modeling the appropriateness and legitimacy of giving to these programs, and (5) subtly highlighting the organization's contributions to these programs. By taking these actions, managers may facilitate employee giving behaviors that trigger the prosocial sensemaking process.

\section{Limitations and Future Directions}

Our research is subject to a number of limitations. First, although both of our studies suggest that giving contributes to affective organizational 
commitment, our cross-sectional data do not rule out the possibility of alternative causal pathways. For example, it is likely that affective commitment is a cause, as well as a consequence, of giving. This is suggested by meta-analyses linking identification and affective commitment to higher levels of citizenship (Harrison et al., 2006; Meyer et al., 2002), as well as by evidence that individuals define their roles more broadly to include citizenship behaviors when they are more affectively committed (Morrison, 1994; Tepper, Lockhart, \& Hoobler, 2001). Research using experimental or longitudinal designs is necessary to substantiate our causal inferences and examine these issues of reciprocal causality. Second, the low response rate in Study 2 raises questions about selection and response biases. We used strategic sampling in Study 1 to obtain a more representative sample, but future research is necessary to examine the generalizability of our findings, which are likely circumscribed to internal rather than external giving behaviors, as well as to employees who want to give.

Third, researchers have emphasized that organizational commitment takes multiple forms (e.g., Meyer et al., 2002), but we focused only on affective commitment. We encourage researchers to investigate how giving influences continuance and normative forms of organizational commitment. We expect giving to strengthen continuance commitment by increasing the perceived costs of withdrawing from the organization. Because giving privately and publicly demonstrates employees' dedication to their organization, employees may feel that they will lose the credit gained for their donations if they leave the organization, and will thus display stronger continuance commitment in order to avoid these costs. On the other hand, we envision competing hypotheses for the effects of giving on normative commitment. Through a dissonance or self-perception mechanism (Bem, 1972), giving may increase normative commitment: employees may justify or interpret their giving behaviors as driven by perceived duty, and will therefore display stronger normative commitment as a result of feeling obligated to the organization. Conversely, through a psychological contract mechanism, giving may decrease normative commitment: employees may see their giving behaviors as fulfilling their obligations, reducing feelings of further obligation. We hope researchers will explore the effects of giving on continuance and normative forms of organizational commitment.

Fourth, in focusing on affective organizational commitment, we did not examine whether giving and receiving are related to distinct psychological and behavioral outcomes. We believe it will be fruitful for researchers to move beyond attitudinal consequences of giving toward a broader examination of behavior and performance effects. By strengthening affective commitment, giving is likely to reduce absenteeism and turnover (CooperHakim \& Viswesvaran, 2005; Meyer et al., 2002), and it may also increase productivity by improving employees' reputations as dedicated, competent contributors (e.g., Flynn, 2003). Fifth, researchers have observed that giving behaviors take multiple forms (Penner et al., 2005), but we did not theoretically or empirically differentiate forms of giving such as giving time versus money, emotional versus instrumental support, and formal versus informal peer support, which may have divergent effects (Penner et al., 2005). Sixth, ESF recipients are anonymous, but in settings in which giving is directed toward identified recipients, researchers should examine whether employees' propensities to give and feel affectively committed are linked to their relational proximity and intimacy with intended or potential recipients (Grant, 2007).

Seventh, giving may strengthen affective commitment through additional mechanisms that are complementary to prosocial sensemaking. We encourage researchers to investigate the possibility that through giving, employees become engaged in community building, increasing their attachment to a community to which they feel they have contributed (e.g., Bacharach, Bamberger, \& Sonnenstuhl, 2001). Eighth, we assumed that all employees value personal prosocial identities as caring individuals and company prosocial identities as caring organizations. It will be worthwhile for future research to investigate whether our model holds for all individuals, or whether individuals with high levels of agreeableness, strong prosocial motives and values, and salient moral identities are more likely to seek and construct prosocial explanations for personal and organizational actions (Aquino \& Reed, 2002; Grant, 2008b; Penner et al., 2005). Ninth, we treated prosocial sensemaking about the self and the company as independent pathways through which giving strengthens commitment, but it is possible that these two pathways may interact. Future research should address whether commitment is highest when employees experience "prosocial fit," or congruence between personal and organizational prosocial identities.

Finally, there are likely several "dark sides" to the present research that do not appear in our data. One risk is that the opportunity to give may elicit high expectations that, if unfulfilled, lead employees to feel that their psychological contracts have been breached and violated (e.g., Thompson \& Bunderson, 2003), generating attributions of hypoc- 
risy and feelings of disenchantment (Cha \& Edmondson, 2006). Such reactions may be particularly likely when giving is forced rather than merely facilitated (Grant, 2008a). A second risk is that employee support programs may harm the very employees they are designed to help, leaving employees financially and emotionally dependent on receiving contributions from others and the organization. A third risk is that managers may take advantage of giving as a cheap alternative to receiving: instead of providing support to employees, managers may simply provide employees with opportunities to give support to others. As such, giving-based commitment may be misappropriated as a form of managerial manipulation, where managers attempt to get more from employees in exchange for less. Critical theorists have expressed concerns about similar risks of empowerment practices (Fineman, 2006), and it will be important for future research to examine the conditions under which giving opportunities are undermined by pressure, cynicism, distrust, and ill intentions.

\section{Conclusion}

As employees continue to become less physically, administratively, and temporally attached to organizations (Cascio, 2003; Pfeffer \& Baron, 1998), scholars need new lenses for understanding how and why organizational commitment develops, and practitioners need new resources for cultivating commitment. Our theoretical perspective on prosocial sensemaking indicates that support programs cultivate stronger affective organizational commitment not only by enabling employees to receive, but also by enabling employees to give. In Weick's (1995) terms, the traditional assumption is that employees judge their affective commitment to organizations by asking, "How can I know how I feel until I see what I get?" Our research suggests that employees also judge their affective commitment to organizations by asking, "How can I know how I feel until I see what I give?"

\section{REFERENCES}

Anderson, J. C., \& Gerbing, D. W. 1988. Structural equation modeling in practice: A review and recommended two step approach. Psychological Bulletin, 103: 411-423.

Aquino, K., \& Reed, A. 2002. The self-importance of moral identity. Journal of Personality and Social Psychology, 83: 1423-1440.

Aronson, E. 1999. The power of self-persuasion. American Psychologist, 54: 875-884.

Bacharach, S. B., \& Bamberger, P., \& McKinney, V. 2000.
Boundary management tactics and logics of action: The case of peer-support providers. Administrative Science Quarterly, 45: 704-736.

Bacharach, S. B., Bamberger, P. A., \& Sonnenstuhl, W. J. 2001. Mutual aid and union renewal: Cycles of logics of action. Ithaca, NY: Cornell University Press.

Bansal, P. 2003. From issues to actions: The importance of individual concerns and organizational values in responding to natural environmental issues. Organization Science, 14: 510-527.

Bem, D. J. 1972. Self-perception theory. In L. Berkowitz (Ed.), Advances in experimental social psychology, vol. 6: 1-62. New York: Academic Press.

Blau, P. M. 1964. Exchange and power in social life. New York: Wiley.

Bolino, M. C. 1999. Citizenship and impression management: Good soldiers or good actors? Academy of Management Review, 24: 82-98.

Brief, A. P, \& Weiss, H. M. 2002. Organizational behavior: Affect in the workplace. In S. T. Fiske, D. L. Schacter, \& C. Zahn-Waxler (Eds.), Annual review of psychology, vol. 53: 279-307. Palo Alto, CA: Annual Reviews.

Cascio, W. F. 2003. Changes in workers, work, and organizations. In W. Borman, R. Klimoski, \& D. Ilgen (Eds.), Handbook of psychology, vol. 12: Industrial and organizational psychology: 401-422. New York: Wiley.

Cha, S. E., \& Edmondson, A. C. 2006. When values backfire: Leadership, attribution, and disenchantment in a values-driven organization. Leadership Quarterly, 17: 57-78.

Cooper-Hakim, A., \& Viswesvaran, C. 2005. The construct of work commitment: Testing an integrative framework. Psychological Bulletin, 131: 241-259.

De Dreu, C. K. W. 2006. Rational self-interest and other orientation in organizational behavior: A critical appraisal and extension of Meglino and Korsgaard (2004). Journal of Applied Psychology, 91: 1245-1252.

Dutton, J. E., Dukerich, J. M., \& Harquail, C. V. 1994. Organizational images and member identification. Administrative Science Quarterly, 39: 239-263.

Edwards, J. R., \& Rothbard, N. P. 2000. Mechanisms linking work and family: Clarifying the relationship between work and family constructs. Academy of Management Review, 25: 178-199.

Elsbach, K. D. 2003. Organizational perception management. In R. M. Kramer \& B. M. Staw (Eds.), Research in organizational behavior, vol. 25: 297-332. Greenwich, CT: JAI Press.

Emerson, R. M. 1976. Social exchange theory. In A. Inkeles, J. Coleman, \& N. Smelser (Eds.), Annual review of sociology, vol. 2: 335-362. Palo Alto, CA: Annual Reviews.

Fineman, S. 2006. On being positive: Concerns and counterpoints. Academy of Management Review, 31: 270-291. 
Flynn, F. J. 2003. How much should I give and how often? The effects of generosity and frequency of favor exchange on social status and productivity. Academy of Management Journal, 46: 539-553.

Flynn, F. J., \& Brockner, J. 2003. It's different to give than to receive: Predictors of givers' and receivers' reactions to favor exchange. Journal of Applied Psychology, 88: 1034-1045.

Fuller, J. B., Barnett, T., Hester, K., \& Relyea, C. 2003. A social identity perspective on the relationship between perceived organizational support and organizational commitment. Journal of Social Psychology, 143: 789-791.

Glaser, B. G., \& Strauss, A. L. 1967. The discovery of grounded theory: Strategies for qualitative research. Aldine: Chicago.

Goodstein, J. 1995. Employer involvement in eldercare: An organizational adaptation perspective. Academy of Management Journal, 38: 1657-1671.

Grant, A. M. 2007. Relational job design and the motivation to make a prosocial difference. Academy of Management Review, 32: 393-417.

Grant, A. M. 2008a. Does intrinsic motivation fuel the prosocial fire? Motivational synergy in predicting persistence, performance, and productivity. Journal of Applied Psychology, 93: 48-58.

Grant, A. M. 2008b. The significance of task significance: Job performance effects, relational mechanisms, and boundary conditions. Journal of Applied Psychology, 93: 108-124.

Harrison, D. A., Newman, D. A., \& Roth, P. L. 2006. How important are job attitudes? Meta-analytic comparisons of integrative behavioral outcomes and time sequences. Academy of Management Journal, 49: 305-325.

Hartwell, T. D., Steele, P., French, M. T., Potter, F. J., Rodman, N. F., \& Zarkin, G. A. 1996. Aiding troubled employees: The prevalence, cost, and characteristics of employee assistance programs in the United States. American Journal of Public Health, 86: 804-808.

Homans, G. C. 1958. Social behavior as exchange. American Journal of Sociology, 63: 597-606.

Hu, L., \& Bentler, P. M. 1999. Cutoff criteria for fit indexes in covariance structure analysis: Conventional criteria versus new alternatives. Structural Equation Modeling, 6: 1-55.

James, L. R., Mulaik, S. A., \& Brett, J. M. 2006. A tale of two methods. Organizational Research Methods, 9: 233-244.

Johnson, A. T. 1986. A comparison of employee assistance programs in corporate and government organizational contexts. Review of Public Personnel Administration, 6(2): 28-41.

Judge, T. A., Thoresen, C. J., Bono, J. E., \& Patton, G. K. 2001. The job satisfaction-job performance relationship: A qualitative and quantitative review. Journal of Applied Psychology, 127: 376-407.
Lee, T. W., Mitchell, T. R., \& Sablynski, C. J. 1999. Qualitative research in organizational and vocational psychology, 1979-1999. Journal of Vocational Behavior, 55: 161-187.

Lilius, J., Worline, M., Maitlis, S., Kanov, J., Dutton, J., \& Frost, P. 2008. Contours of compassion at work. Journal of Organizational Behavior, 29: 193-218.

Maitlis, S. 2005. The social processes of organizational sensemaking. Academy of Management Journal, 48: $21-49$.

Mathieu, J. E., \& Zajac, D. M. 1990. A review and metaanalysis of the antecedents, correlates, and consequences of organizational commitment. Psychological Bulletin, 108: 171-194.

Mayer, R. C., Davis, J. H., \& Schoorman, D. F. 1995. An integrative model of organizational trust. Academy of Management Review, 20: 709-734.

McBroom, W. H., \& Reed, F. W. 1992. Toward a reconceptualization of attitude-behavior consistency. Social Psychology Quarterly, 55: 205-216.

Meglino, B. M., \& Korsgaard, M. A. 2004. Considering rational self-interest as a disposition: Organizational implications of other orientation. Journal of Applied Psychology, 89: 946-959.

Meyer, J. P., \& Allen, N. J. 1991. A three-component conceptualization of organizational commitment. Human Resource Management Review, 1: 61-89.

Meyer, J. P., Becker, T. E., \& Vandenberghe, C. 2004. Employee commitment and motivation: A conceptual analysis and integrative model. Journal of Applied Psychology, 89: 991-1007.

Meyer, J. P., Smith, C. A., \& Allen, N. J. 1993. Commitment to organizations and occupations: Extension and test of a three-component conceptualization. Journal of Applied Psychology, 78: 538-551.

Meyer, J. P., Stanley, D. J., Herscovitch, L., \& Topolnytsky, L. 2002. Affective, continuance, and normative commitment to the organization: A meta-analysis of antecedents, correlates, and consequences. Journal of Vocational Behavior, 61: 20-52.

Miller, D. T. 1999. The norm of self-interest. American Psychologist, 54: 1053-1060.

Morrison, E. W. 1994. Role definitions and organizational citizenship behavior: The importance of employee's perspective. Academy of Management Journal, 37: 1543-1567.

Mowday, R. T., \& Sutton, R. I. 1993. Organizational behavior: Linking individuals and groups to organizational contexts. In L. W. Porter \& R. M. Rosenzweig (Eds.), Annual review of psychology, vol. 44: 195229. Palo Alto, CA: Annual Reviews.

Orbuch, T. L. 1997. People's accounts count: The sociology of accounts. In J. Hagan \& K. S. Cook (Eds.), Annual review of sociology, vol. 23: 455-478. Palo Alto, CA: Annual Reviews.

Penner, L. A., Dovidio, J. F., Piliavin, J. A., \& Schroeder, D. A. 2005. Prosocial behavior: Multilevel perspec- 
tives. In S. T. Fiske, D. L. Schacter, \& A. E. Kazdin (Eds.), Annual review of psychology, vol. 56: 365392. Palo Alto, CA: Annual Reviews.

Perry-Smith, J. E., \& Blum, T. C. 2000. Work-family human resource bundles and perceived organizational performance. Academy of Management Journal, 43: 1107-1117.

Pfeffer, J. 2006. Working alone: Whatever happened to the idea of organizations as communities? In E. E. Lawler \& J. O'Toole (Eds.), America at work: Choices and challenges: 3-22. New York: Palgrave Macmillan.

Pfeffer, J., \& Baron, J. N. 1988. Taking the workers back out: Recent trends in the structuring of employment. In L. L. Cummings \& B. M. Staw (Eds.), Research in organizational behavior, vol. 10: 257-303. Greenwich, CT: JAI Press.

Pittinsky, T. L., \& Shih, M. J. 2004. Knowledge nomads: Organizational commitment and worker mobility in positive perspective. American Behavioral Scientist, 47: 791-807.

Podsakoff, P. M., MacKenzie, S. B., \& Lee, J. 2003. Common method biases in behavioral research: A critical review of the literature and recommended remedies. Journal of Applied Psychology, 88: 879-903.

Pratt, M. G. 2000. The good, the bad, and the ambivalent: Managing identification among Amway distributors. Administrative Science Quarterly, 45: 456-493.

Quinn, R. P., \& Shepard, L. G. 1974. The 1972-1973 quality of employment survey. Ann Arbor: Institute for Social Research, University of Michigan.

Rhoades, L., \& Eisenberger, R. 2002. Perceived organizational support: A review of the literature. Journal of Applied Psychology, 87: 698-714.

Riketta, M. 2002. Attitudinal organizational commitment and job performance: A meta-analysis. Journal of Organizational Behavior, 23: 257-266.

Rogelberg, S. G., \& Stanton, J. M. 2007. Introduction: Understanding and dealing with organizational survey nonresponse. Organizational Research Methods, 10: 195-209.

Shamir, B. 1990. Calculations, values, and identities: The sources of collectivistic work motivation. Human Relations, 43: 313-332.

Shrout, P. E., \& Bolger, N. 2002. Mediation in experimental and non-experimental studies: New procedures and recommendations. Psychological Methods, 7: 422-445.

Somers, M. J. 1995. Organizational commitment, turnover and absenteeism: An examination of direct and interaction effects. Journal of Organizational Behavior, 16: 49-58.

Stine, R. 1989. An introduction to bootstrap methods. Sociological Methods \& Research, 18: 243-291.

Swann, W. B., Polzer, J. T., Seyle, D., \& Ko, J. 2004. Finding value in diversity: Verification of personal and social self-views in diverse groups. Academy of Management Review, 29: 9-27.

Tepper, B. J., Lockhart, D., \& Hoobler, J. 2001. Justice, citizenship, and role definition effects. Journal of Applied Psychology, 86: 789-796.

Thompson, J. A., \& Bunderson, J. S. 2003. Violations of principle: Ideological currency in the psychological contract. Academy of Management Review, 28: 571586.

Trice, H. M., \& Beyer, J. M. 1984. Employee assistance programs: Blending performance-oriented and humanitarian ideologies to assist emotionally disturbed employees. Research in Community \& Mental Health, 4: 245-297.

Turban, D. B., \& Greening, D. W. 1997. Corporate social performance and organizational attractiveness to prospective employees. Academy of Management Journal, 40: 658-672.

Weick, K. E. 1995. Sensemaking in organizations. Thousand Oaks, CA: Sage.

Weick, K. E., Sutcliffe, K. M., \& Obstfeld, D. 2005. Organizing and the process of sensemaking. Organization Science, 16: 409-421.

Weiner, B. 1985. An attributional theory of achievement motivation and emotion. Psychological Review, 92: $548-573$

Wrzesniewski, A., Dutton, J. E., \& Debebe, G. 2003. Interpersonal sensemaking and the meaning of work. In R. M. Kramer \& B. M. Staw (Eds.), Research in organizational behavior, vol. 25: 93-135. Greenwich, CT: JAI Press.

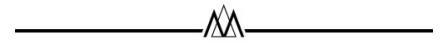

Adam M. Grant (agrant@unc.edu) is an assistant professor of organizational behavior at the University of North Carolina at Chapel Hill. He received his Ph.D. from the University of Michigan. His research focuses on job design, work motivation, prosocial and proactive behaviors, and employee well-being.

Jane E. Dutton (janedut@umich.edu) is the Robert L. Kahn Distinguished University Professor of Business Administration and Psychology at the University of Michigan. Her current research focuses on generative meaning processes in organizations, high-quality relationships, and compassion in organizations. These interests are all related to a focus and interest in positive organizational scholarship.

Brent D. Rosso (brosso@umich.edu) is a doctoral candidate in the Departments of Organizational Psychology and Management \& Organizations at the University of Michigan. His research focuses on human flourishing in the workplace and on flourishing organizations, with particular emphasis on prosocial behavior, meaningful work, and creative teams.

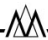

